\title{
Preliminary Report: STOIC CGCM Intercomparison Equatorial Sections
}

\author{
M. Davey \\ M. Huddleston \\ K.R. Sperber
}

March 1, 1999

This is an informal report intended primarily for internal or limited external distribution. The opinions and conclusions stated are those of the author and may or may not be those of the Laboratory.

Work performed under the auspices of the U.S. Department of Energy by the Lawrence Livermore National Laboratory under Contract W-7405-ENG-48. 


\section{DISCLAIMER}

This document was prepared as an account of work sponsored by an agency of the United States Government. Neither the United States Government nor the University of California nor any of their employees, makes any warranty, express or implied, or assumes any legal liability or responsibility for the accuracy, completeness, or usefulness of any information, apparatus, product, or process disclosed, or represents that its use would not infringe privately owned rights. Reference herein to any specific commercial product, process, or service by trade name, trademark, manufacturer, or otherwise, does not necessarily constitute or imply its endorsement, recommendation, or favoring by the United States Government or the University of California. The views and opinions of authors expressed herein do not necessarily state or reflect those of the United States Government or the University of California, and shall not be used for advertising or product endorsement purposes.

This report has been reproduced directly from the best available copy.

Available to DOE and DOE contractors from the Office of Scientific and Technical Information P.O. Box 62, Oak Ridge, TN 37831

Prices available from (423) 576-8401

Available to the public from the National Technical Information Service

U.S. Department of Commerce 5285 Port Royal Rd. Springfield, VA 22161 


\title{
Preliminary report: STOIC CGCM intercomparison
}

\section{Equatorial sections}

\author{
Michael Davey, Matt Huddleston \\ Ocean Applications, UK Meteorological Office \\ Ken Sperber \\ PCMDI, Lawrence Livermore National Laboratory, California
}

March 1999

\section{Background}

An intercomparison and assessment of the tropical behaviour of coupled general circulation models (CGCMs) is being carried out, to identify common strengths and weaknesses and thus guide future CGCM development. The work is being carried out as part of the CLIVAR climate research programme, as a WG-SIP (Working Group on Seasonal to Interannual Prediction) project called STOIC (Study of Tropical Oceans In CGCMs), organised by Michael Davey. This project complements a companion sub-project called ENSIP (El Niño Simulation Intercomparison Project) organised by Mojib Latif (MaxPlanck-Institute for Meteorology) that focusses on equatorial Pacific CGCM behaviour (Latif et al. 1999).

Previous coupled model assessments (Mechoso et al. 1995, Neelin et al. 1992, and ENSIP) have focussed on tropical Pacific behaviour. The aim of STOIC is to look at model performance in all tropical ocean regions.

This status report contains a sample of the STOIC assessment work, highlighting mean and interannual equatorial sea surface temperatures and zonal windstresses. The intention is to submit STOIC and ENSIP papers in mid-1999 for publication together in a refereed journal.

\section{The CGCM data}

The basic data requested were monthly mean fields of tropical sea surface temperature (SST), surface wind stress, and upper ocean heat content from typical 20 year periods of coupled model integration. Contributions from 24 CGCMs worldwide have been collected centrally at Lawrence Livermore National Laboratory and converted to a common format. The data were copied to the Met. Office, and converted to a format convenient for local analysis. Most data were submitted to Lawrence Livermore National Laboratory in 1997, some in 1998. In the cases where more than 20 years of data were submitted, the analysis has been based on the last 20 years. Typically the CGCMs had run in coupled mode for several model-years prior to the 20-year sample: checks for drift showed no significant trends in SST or 
windstress, though some drift in heat content was apparent in some models.

The CGCMs vary considerably in configuration. Some basic information is provided in Table 1. Many of the CGCMs or their ocean and atmosphere components have been analysed individually and described in separate publications. Some have relatively low resolution, and are designed for multi-century integrations for low frequency climate variability research, while others have high resolution (particularly in the oceanic equatorial regions) and are aimed at seasonal scales. Some have no form of flux adjustment (constraint toward observed climatology), while others have varying degrees of climate control.

The models are in the main designed for research on climate variability on interannual and longer timescales. In the design process, some tuning to obtain realistic mean fields and variability will have been carried out. Among the flux-adjusted group, the nature and degree of flux adjustment varies in each model: some are more tightly constrained to observed climatology than others, and they are not all constrained by the same climatologies.

While most models are true GCMs, with comprehensive physics and 'primitive equation' dynamics, there are two main exceptions. The LAMONT model has considerably simplified physics and dynamics (the ocean and atmosphere components effectively have 2-level vertical resolution and are not GCMs), and was designed specifically for tropical Pacific interannual variability research. The DKRZ-LSG has modified (large-scale-geostrophic) ocean dynamics and relatively low horizontal resolution that is detrimental to tropical behaviour, and was designed to study centennial and longer timescales.

The Met. Office model data submitted for ENSIP and STOIC are from a trial version of HADCM3, the current Hadley Centre coupled climate model. In most respects the trial version is the same as full HADCM3. (In the trial version there was overactive convection in the tropical Asian sector that was reduced for the final HADCM3 version by adjustments to atmospheric parameters.) Data from the control run of the full HADCM3 version have been included in the STOIC intercomparison - the last 20 years of the 1000 year control run were selected (behaviour in the selected years is representative of general HADCM3 behaviour). In the diagrams for this report, results for the trial and full versions are labelled UKMO and UKMO-CM3 respectively.

\section{Outline of the analysis}

Surface windstress, SST and upper ocean structure are key ingredients in tropical ocean-atmosphere dynamics and interaction. The mean climatology, seasonal cycle and interannual variability of each of these fields form the basis of the STOIC assessment. Interactions between these different fields, and connections from one ocean basin to another, are also being investigated by identifying and analysing several key regions.

For comparison, monthly gridded datasets based on analyses of observations have been obtained from various sources: SST from the Met. Office GISST3 SST/sea-ice dataset; surface windstress from Southampton Oceanography Centre (SOC) and from the WM-COADS dataset; and upper ocean heat content from Scripps Institution of Oceanography (see table 2).

In the following sections some selected concise graphical examples of the comparison between CGCMs 
and observations are provided for equatorial SST and zonal windstress. As well as graphical comparisons, numerical measures of several quantities are also being calculated: tables of these will be provided in a final report, and these will provide objective measures that can be used to assess the performance of future CGCM versions.

\section{Equatorial SST examples}

\subsection{Mean equatorial SST}

Mean SST in the equatorial strip 2N-2S was calculated for each model and the GISST observational analysis (the latter for the standard climatology 1961-90). Results are shown in Fig. 1. Models that use some form of adjustment to climatology are gathered in Fig. 1a, while those without flux adjustment are in Fig. 1b. The GISST mean is provided in each section for comparison. (Spikes that appear in parts of 1a are likely to be due to values over land that have not been eliminated. Note that some models only provide Pacific or Pacific + Atlantic ocean data: see table 1.)

For models with flux adjustment, errors in the atmospheric model fluxes into the ocean, and errors in the ocean components, will both be compensated.

In Fig. 1a the zonal gradient of SST is well represented by the models in each of the tropical oceans. The striking feature is the systematic displacement from observed values. (In particular, DKRZ-LSG is consistently about 3C too cool in each ocean: recall however that DKRZ-LSG is not intended for tropical climate simulation.) DKRZ-LSG apart, positive and negative errors of about $1 \mathrm{C}$ or less occur in each ocean. The errors are not necessarily consistent betwen oceans: NRL has a positive bias in the Indian ocean, but a negative bias in most of the Pacific. MRI is close to observed SST in the Indian ocean, but is substantially too warm in the west Pacific.

The models without flux adjustment have more freedom to depart from observed climatology, and this is reflected in the wider range of SST climatologies in Fig. 1b. In the Pacific sector, an important good feature is that the strong east-west SST gradient is by and large correct - in earlier generations of CGCMs, the gradient was often much flatter or even reversed. However, most models have a systematic cold bias (2C or more in many cases) in much of the Pacific. In the east Pacific, the observed mean SST rises approaching the South American coast. Most models exaggerate this rise, with positive (and large) SST errors common in this region. From other assessments, warm SST errors adjacent to the South American coast in CGCMs are typically related to errors in the simulation of stratus cloud.

The situation in the Atlantic sector is worse. Observed mean SST decreases from west to east, but nearly all the CGCMs have the opposite gradient. In nearly all the models SST is biased cold in the west equatorial Atlantic, by up to $3 \mathrm{C}$, but biased warm in the east equatorial Atlantic. This is a serious common error that requires explanation.

In the equatorial Indian ocean the CGCMs generally have the right zonal gradient, with SST rising rapidly from relatively cold levels at the African coast, where upwelling of cold water occurs during the boreal summer season. As in the Pacific, most models have a cold bias. The UKMO and UKMO-CM3 
models are an exception, with a warm Indian sector bias that connects to a very warm far west Pacific SST bias.

\subsection{Equatorial SST variability}

Considerable attention has been given to interannual ocean-atmosphere behaviour, with regard to the generation of ENSO events that dominate observed interannual variability. A well-known weakness of coupled GCMs revealed in previous intercomparison studies is the difficulty in producing realistic levels and distributions of SST variability. While observations show maximum variability in the east equatorial Pacific, CGCMs often have the maximum displaced well to the west.

The standard deviation (sd) of interannual SST anomalies in the 2N-2S equatorial strip is shown in Fig 2. The observed sd was calculated for the well-observed 20-year period 1971-90. Largest sd is found in the Pacific sector, east of the dateline. There is a smaller peak in the central Atlantic, and variability in the Indian ocean is relatively low. For the models, a similar (large) range of behaviour is found for the flux-adjusted and non-flux-adjusted groups. In the equatorial Pacific, only CCSR has amplitude and distribution close to the observations. Some models have central-east Pacific maxima, but with sd much larger or smaller than observed. Others have maxima around or west of the dateline. CCC and DKRZ-LSG have very low sd. The UKMO and UKMO-CM3 models both have too much SST variability. In the west Pacific UKMO has exceptionally high sd, which is substantially reduced (but still too high) in UKMO-CM3.

In the Indian sector, most models have a realistic level of variability. Particular exceptions are CCSR, NCAR-WM and MRI which have very strong (up to twice observed) sd. NCAR-WM also has very high Atlantic sd, well above even Pacific levels. In the Atlantic region the models without flux adjustment generally perform better than those with flux adjustment: the latter all have low sd in the central-east Atlantic.

\section{Equatorial zonal windstress examples}

4.1 Annual mean equatorial zonal windstress

Mean zonal windstress was calculated for a $5 \mathrm{~N}-5 \mathrm{~S}$ equatorial belt. The SOC climatology is an average for 1980-93, whereas the WM-COADS climatology is for 1970-89. The two climatologies are in close agreement, with the main difference in the west Pacific, as can be seen in Fig. 3.

Results for flux-adjusted models are provided in Fig. 3a: the overall impression is that most of the models fit the observations quite well in the Pacific and Atlantic sectors. In the Pacific region all models have a central Pacific easterly windstress maximum positioned not far from the observed location (210E), with magnitude deceasing to near-zero at the western and eastern Pacific boundaries. The magnitude of the model Pacific maxima varies substantially, from 0.4 to $0.8 \mathrm{Nm}^{-2}$ compared with the observed value of 0.55. These discrepancies are probably due to differences in the atmospheric models: the highest (DKRZ) 
and lowest (CCC) magnitudes are for models with SST closely constrained to observed climatology (see Fig. 1a).

In the equatorial Atlantic the models have strong easterlies at the western boundary, declining to near zero at the African boundary, like the observed behaviour. The observations show a distinct amplitude maximum at 320E: most models do not have this feature, with maxima located at the South American boundary (310E) instead. Several models underestimate the zonal windstress magnitude in the west and central Atlantic, but the zonal gradient is about right.

Results are more variable in the Indian sector. Several models seriously underestimate the westerly windstress in the central Indian ocean (observed maximum near 80E): some have mean easterlies in this area. These errors may reflect problems in representing the monsoon cycle over the Indian ocean: this has been investigated further by analysing the seasonal cycle in the various models.

Mean zonal windstresses for models without flux adjustment are shown in Fig. 3b. As might be expected, there is much more variety of behaviour in the Pacific region, compared to the flux-adjusted group. Generally the models are close to the observations in the east Pacific, but in the west-central Pacific all models (with the exception of CERFACS) differ substantially from the observations. In the central Pacific the easterly windstresses are underestimated by many models, whereas in the west Pacific the windstress is strongly easterly in most of these models, instead of near zero as observed. These windstress errors are associated with the systematic SST errors seen in Fig. 1b, which are also large in the west-central Pacific. However, note that the two models with the best central Pacific SST (COLA and NCAR-WM) have the weakest central Pacific windstresses!

In the equatorial Atlantic the windstresses are more consistent. Moreover, the zonal gradients are quite similar to that observed: this is surprising in view of the poor zonal SST gradients found in Fig. 1b. Further investigation is needed to explain this contrast in windstress and SST performance. Part of the explanation may be that the model mean windstresses are nearly all substantially weaker (less easterly) than observed in the equatorial Atlantic.

Over the Indian ocean the models with no flux adjustment also do not reproduce the observed westerly maximum. Three models have mean easterlies throughout the equatorial Indian sector: these also have overly strong easterlies near the African coast.

\subsection{Interannual variability of equatorial zonal windstress}

The standard deviation of interannual zonal windstress anomalies in the $5 \mathrm{~N}-5 \mathrm{~S}$ equatorial strip is shown in Fig 4. (Note: the standard deviations are calculated after the 5N-5S average is applied to the windstress data. If instead the standard deviations are calculated first then the observed maximum values are about 20The observations show a maximum in the Pacific, near the dateline, and high variability over much of the central Pacific region which is associated with the eastward displacement of convection during El Niño events. Variability is also high in the eastern Indian ocean. The SOC and WM-COADS results have similar spatial distribution, but SOC generally has larger magnitude.

The prominent feature of all the CGCMs is the lack of variability in the central Pacific, with standard 
deviations typically less than $50 \%$ of the observed level. For many models the standard deviations are also much lower than observed levels in the Indian Ocean sector. However, in the Atlantic sector the models have standard deviations comparable with (and in some cases substantially larger than) observed levels.

The lack of model windstress variability could occur because the models underestimate variability on shorter timescales while performing better at longer timescales. (Recall that monthly data are being used.) However, the same calculation after a 7-month running mean is applied to the data leads to the same conclusion - most models seriously underestimate central Pacific variability.

\section{Summary}

This comparison of data from coupled GCMs with observed tropical ocean and atmosphere behaviour highlights common strengths and weaknesses. There is evidence of substantial progress, in that many CGCMs now run without flux corrections for many years (decades) without incurring large climate drift. Several CGCMs are capable of generating substantial ENSO-like interannual variability.

There is also evidence of some common defects. While climate drift has been reduced by model improvements (and, in the flux-adjusted cases, by constraints to observed climatology), several substantial systematic errors remain. As discussed in section 3, model mean zonal SST gradients in the equatorial Atlantic often are the opposite of that observed. Mean zonal windstresses are particularly poor in the west equatorial Pacific.

With regard to interannual variability, the location of maximum SST variability is still often misplaced in the central (or even west) equatorial Pacific. Perhaps the most unexpected result is the lack of interannual variability in the zonal windstresses, which is generally much lower than that observed, particularly in the important central Pacific area.

\section{Acknowledgements}

K.R. Sperber was supported under the auspices of the U.S. Department of Energy Environmental Sciences Division at the Lawrence Livermore National Laboratory under Contract W-7405-ENG-48.

The model data were kindly provided by a long list of contributors, who will be co-authors on the final report. Simon Josey kindly provided the SOC windstress dataset. 


\section{References}

Latif, M, K. Sperber et al., 1999. The El Niño simulation intercomparison project. Report in preparation.

Mechoso, C., A.W. Robertson et al., 1995. The seasonal cycle over the tropical Pacific in general circulation models. Mon Weath Rev, 123, 2825-2838.

Neelin, D., M. Latif et al., 1992. Tropical air-sea interaction in general circulation models. Clim. Dyn., 7, 73-104.

\section{Figure caption}

Fig. 1: Annual mean SST in the equatorial strip 2N-2S, as observed and for (a) CGCMs with flux adjustment, (b) CGCMs without flux adjustment.

Fig. 2: Interannual standard deviation of SST in the equatorial strip $2 \mathrm{~N}-2 \mathrm{~S}$, as observed and for (a) CGCMs with flux adjustment, (b) CGCMs without flux adjustment.

Fig. 3: Annual mean zonal windstress in the equatorial strip 5N-5S, as observed and for (a) CGCMs with flux adjustment, (b) CGCMs without flux adjustment.

Fig. 4: Interannual standard deviation of zonal windstress in the equatorial strip $5 \mathrm{~N}-5 \mathrm{~S}$, as observed and for (a) CGCMs with flux adjustment, (b) CGCMs without flux adjustment. (Note: the standard deviations are calculated after the $5 \mathrm{~N}-5 \mathrm{~S}$ average.) 


\section{Table 1: STOIC models}

Ln denotes $n$ vertical levels. Rn and Tn denote rhomboid and triangular spectral horizontal resolution. $\mathrm{n}-\mathrm{m}$ denotes irregular oceanic latitudinal resolution with grid spacing $\mathrm{n}$ at equator increasing poleward to $\mathrm{m}$.

\begin{tabular}{|c|c|c|c|c|}
\hline name & $\begin{array}{l}\text { atmos grid } \\
\text { (long } \mathrm{x} \text { lat) }\end{array}$ & $\begin{array}{l}\text { ocean grid } \\
\text { (lat } \mathrm{x} \text { long) }\end{array}$ & domain & flux adjustment? \\
\hline BMRC & R21 L9 & $0.5-5.9 \times 2$ L25 & global & no \\
\hline $\mathrm{CCC}$ & T32 L10 & $1.8 \times 1.8 \mathrm{~L} 29$ & global & heat, P-E \\
\hline CCSR & T21 L20 & $0.5-2 \times 2.5 \mathrm{~L} 20$ & global & poleward of lat55 \\
\hline CERFACS & T42 L31 & $0.33-1.5 \times 0.75 \mathrm{~L} 28$ & trop Pac & no \\
\hline $\begin{array}{l}\text { CEA-DSM } \\
\text { (SACLAY) }\end{array}$ & 5.6x50pts L11 & $1.0-13 \times 4$ L31 & global & no \\
\hline COLA & T30 L18 & $1-3 \times 3$ L 20 & $\mathrm{Pac}$, Atl & no \\
\hline DKRZ & T42 L19 & $0.5-2.8 \times 2.8 \mathrm{~L} 11$ & global & heat and P-E \\
\hline DKRZ LSG & T21 L19 & $4 \times 4$ L11 & global & heat, P-E, mom \\
\hline GFDL R15 & R15 L9 & $3.75 \times 4.5 \mathrm{~L} 12$ & global & heat, P-E \\
\hline GFDL R30 & R30 L14 & $2.2 \times 1.875 \mathrm{~L} 18$ & global & heat, P-E \\
\hline HAWAII & $? ?$ & $? ?$ & Pacific & $? ?$ \\
\hline IPSL TOGA & 5.6x50pts L11 & $0.33-1.5 \times 0.75 \mathrm{~L} 28$ & Pacific & no \\
\hline IPSL LMD & $3.75 x 75$ pts L15 & $0.5-1.5 \times 2$ L31 & global & no \\
\hline JMA & T42 L21 & $0.5-2 \times 2.5 \mathrm{~L} 20$ & global & no \\
\hline LAMONT & $5.625 \times 2$ & $0.5 \times 2 \mathrm{~L} 2$ & trop Pac & anomaly couple \\
\hline MPI & T42 L19 & $0.5-2.8 \times 2.8$ L20 & global & no \\
\hline MRI & $4 \times 5 \mathrm{~L} 15$ & $0.5-2 \times 2.5 \mathrm{~L} 21$ & global & heat, P-E \\
\hline NCAR CSM & T42 L18 & $1.2 \times 2.4 \mathrm{~L} 45$ & global & no \\
\hline NCAR WM & R15 L9 & $1 \times 1 \mathrm{~L} 20$ & global & no \\
\hline NCEP & T40 L18 & $0.33-1 \times 1.5$ L28 & trop Pac & 1-way anom \\
\hline NRL & T39 L12 & $0.5-2 \times 2 \mathrm{~L} 25$ & $\mathrm{Pac}$ & $? ?$ \\
\hline UCLA & $4 \times 5 \mathrm{~L} 15$ & $0.33 \times 1 \mathrm{~L} 27$ & $? ?$ & no \\
\hline UKMO & $3.75 \times 2.5$ L19 & $1.25 \times 1.25 \mathrm{~L} 20$ & global & no \\
\hline UKMO-CM3 & $3.75 \times 2.5 \mathrm{~L} 19$ & $1.25 \times 1.25 \mathrm{~L} 20$ & global & no \\
\hline
\end{tabular}


Table 2: observation datasets

The datasets contain monthly values for the years indicated. Tau denotes surface wind stress. HCO denotes upper ocean $(0-400 \mathrm{~m})$ heat content.

$\begin{array}{lllll}\text { field } & \text { source } & \text { lat } \mathrm{x} \text { long } & \text { domain } & \text { years } \\ \text { SST } & \text { GISST3 } & 1 \times 1 & \text { global } & 1870-1998 \\ \text { tau } & \text { SOC } & 1 \times 1 & 30 \text { S-30N } & 1980-1993 \\ \text { tau } & \text { WM-COADS } & 1 \times 1 & \text { global } & 1950-1989 \\ & & & & \\ \text { HCO } & \text { SIO } & 2 \times 5 & 61 S-61 \mathrm{~N} & 1950-1993\end{array}$

Table. 2 
Annual mean 2N-2S SST - flux corrected

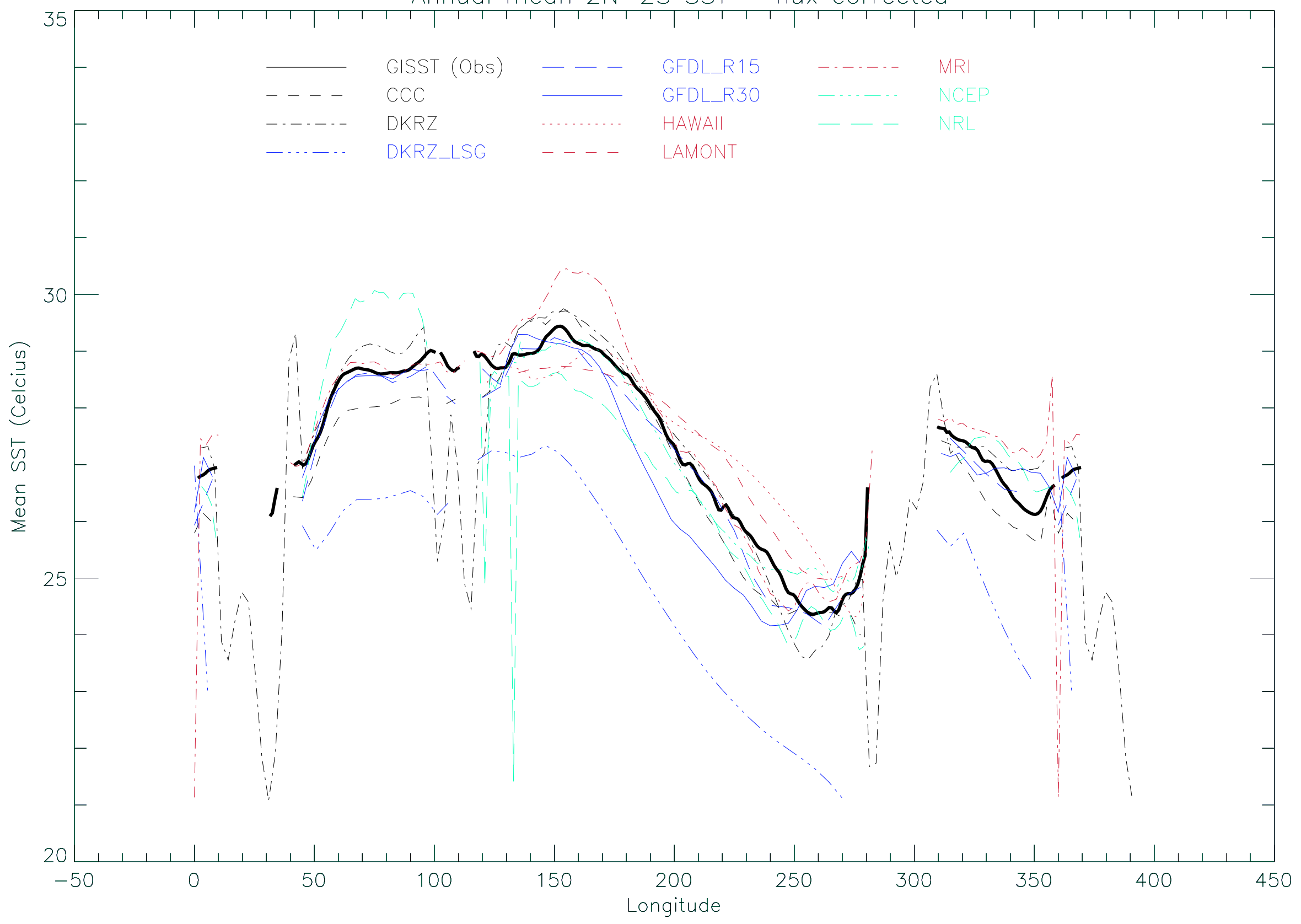




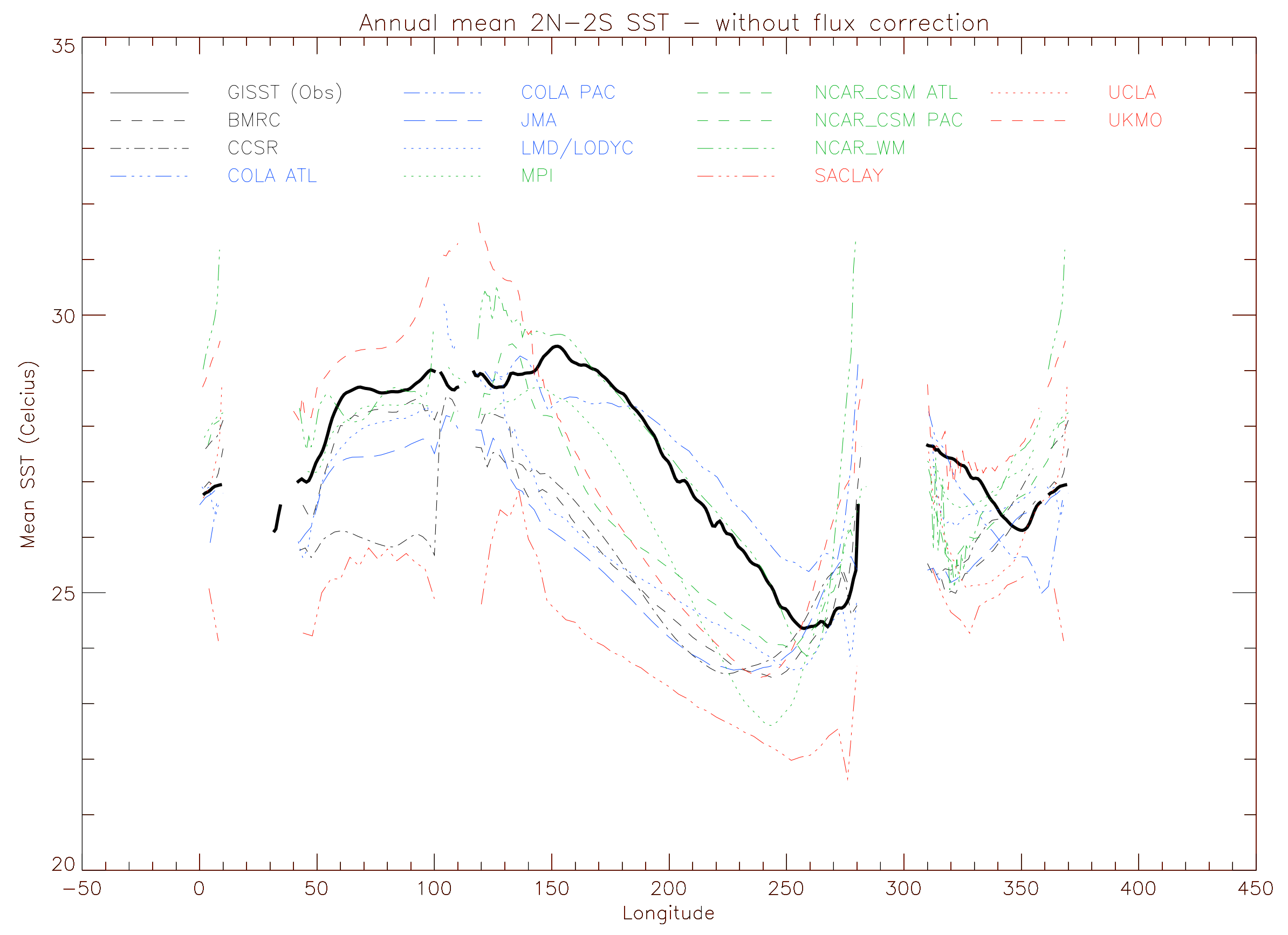


Mean 2N-2S standard deviation of SST - with flux correction

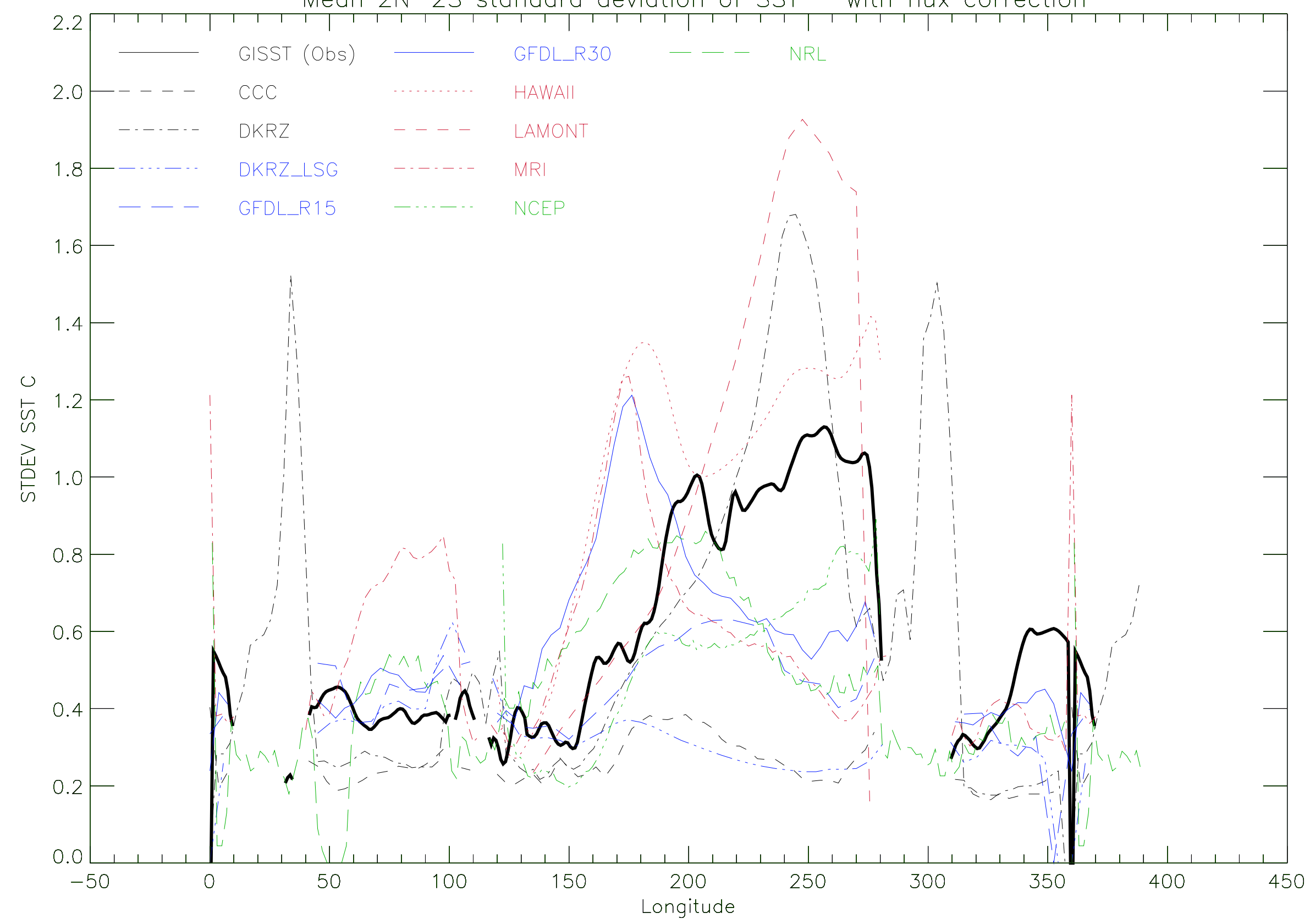


Mean 2N-2S standard deviation of SST - without flux correction

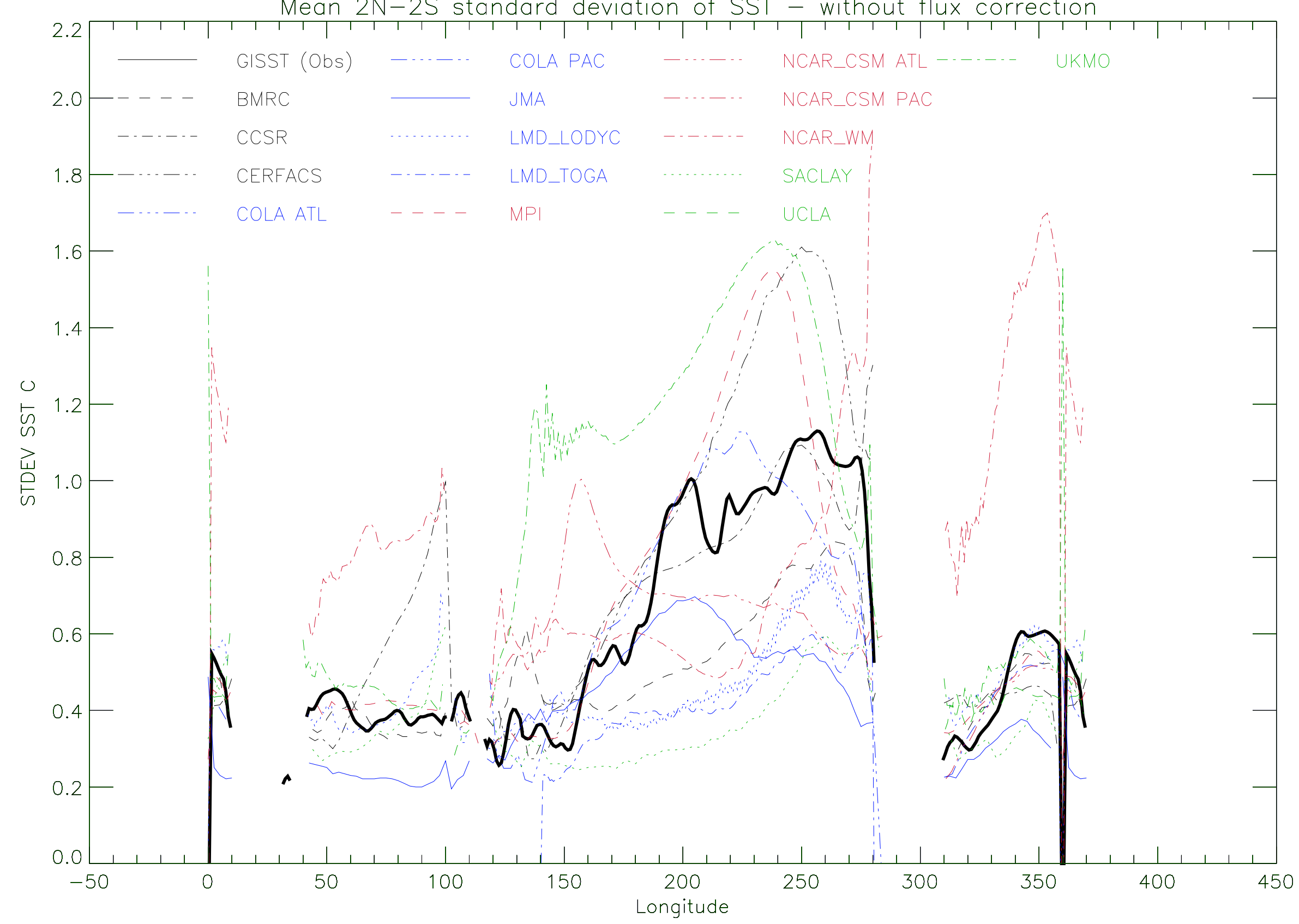




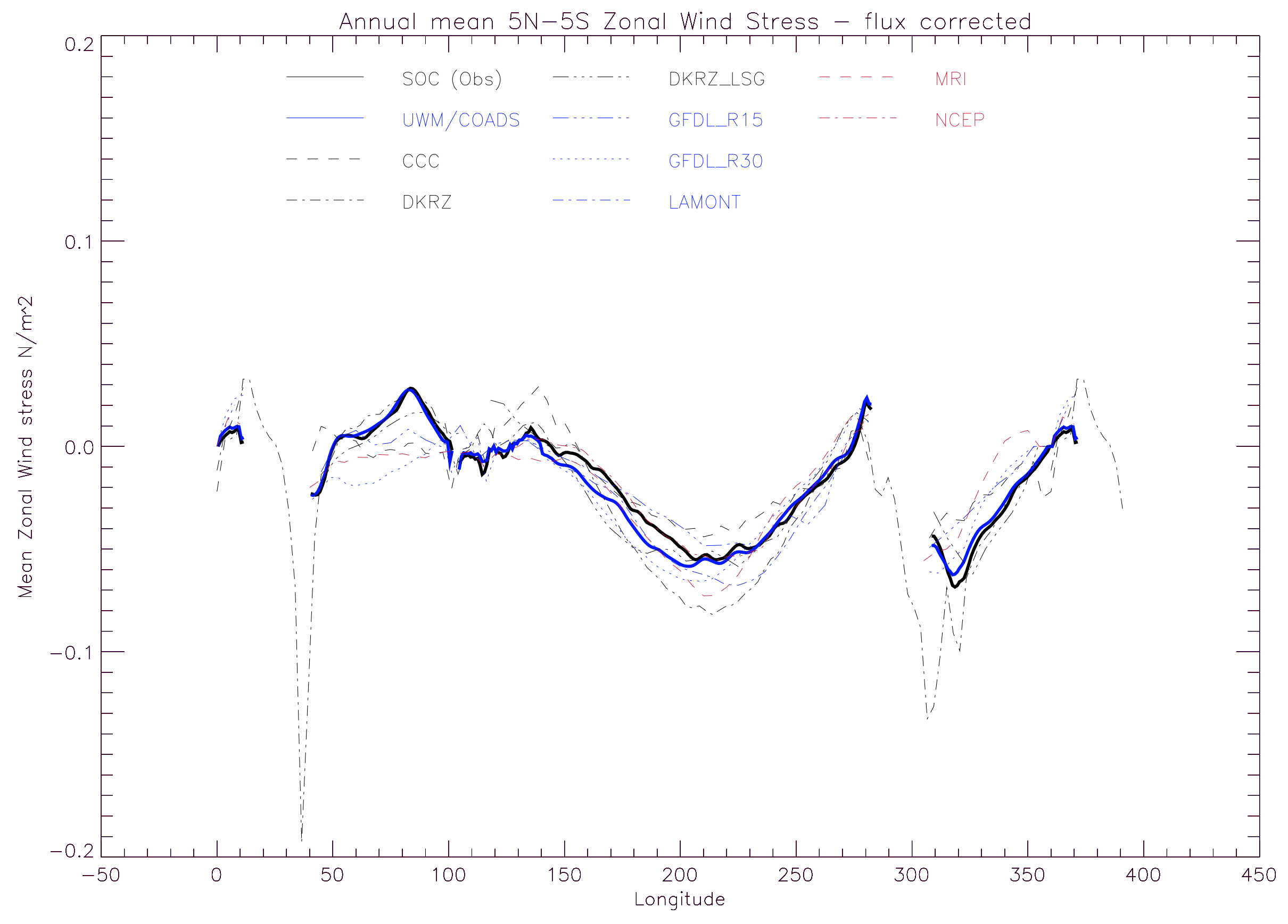


Annual mean 5N-5S Zonal Wind Stress - without flux correction

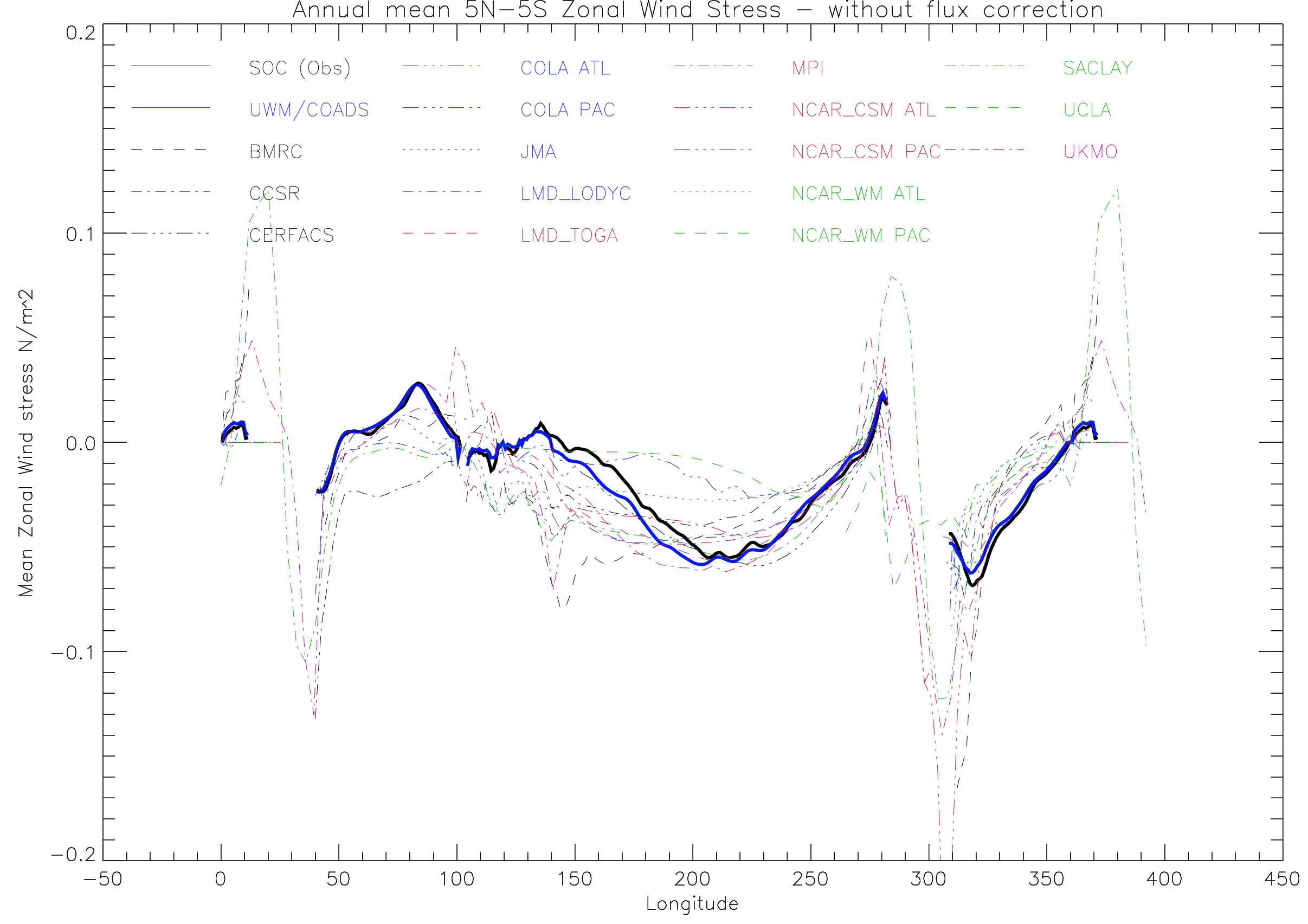




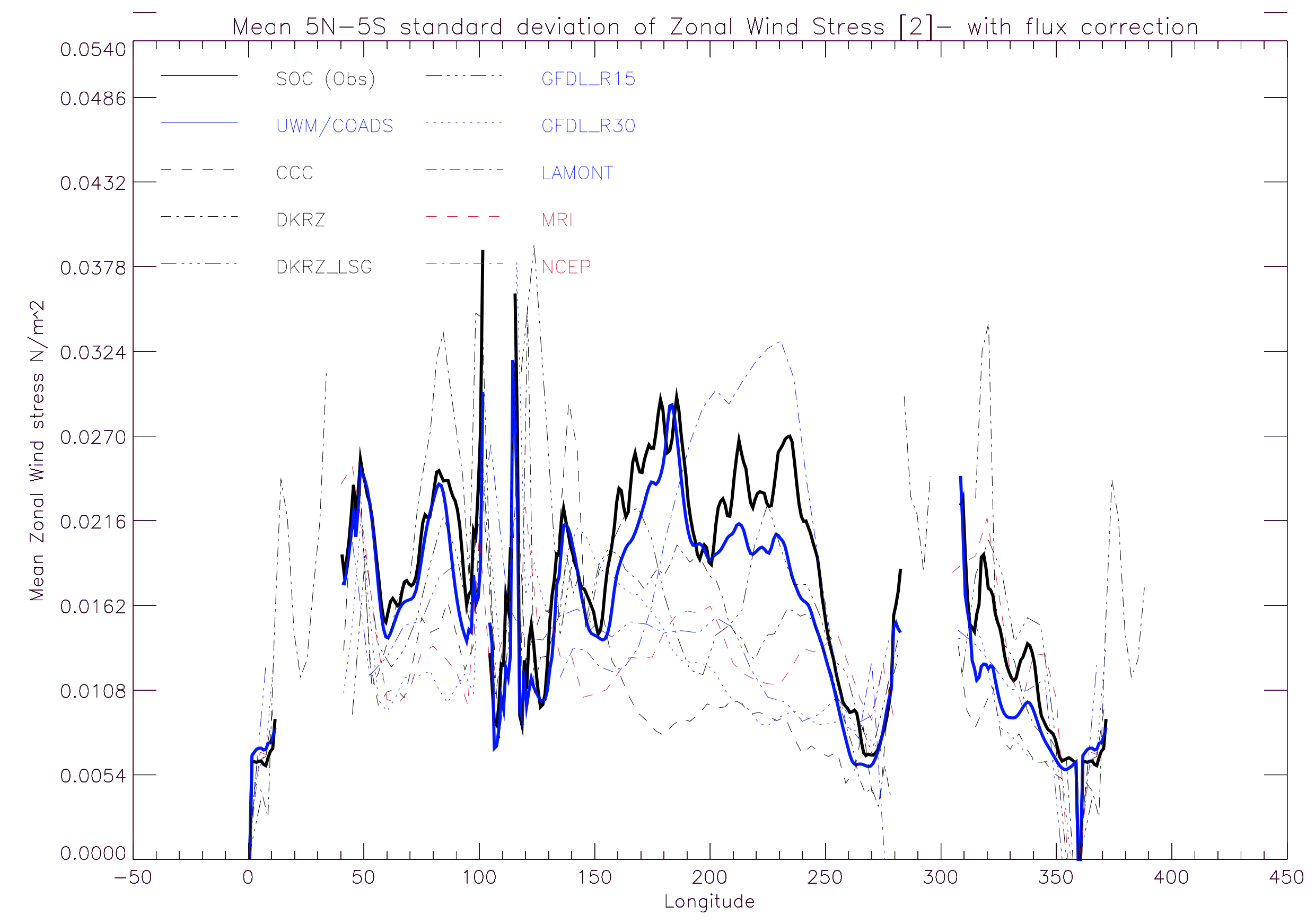




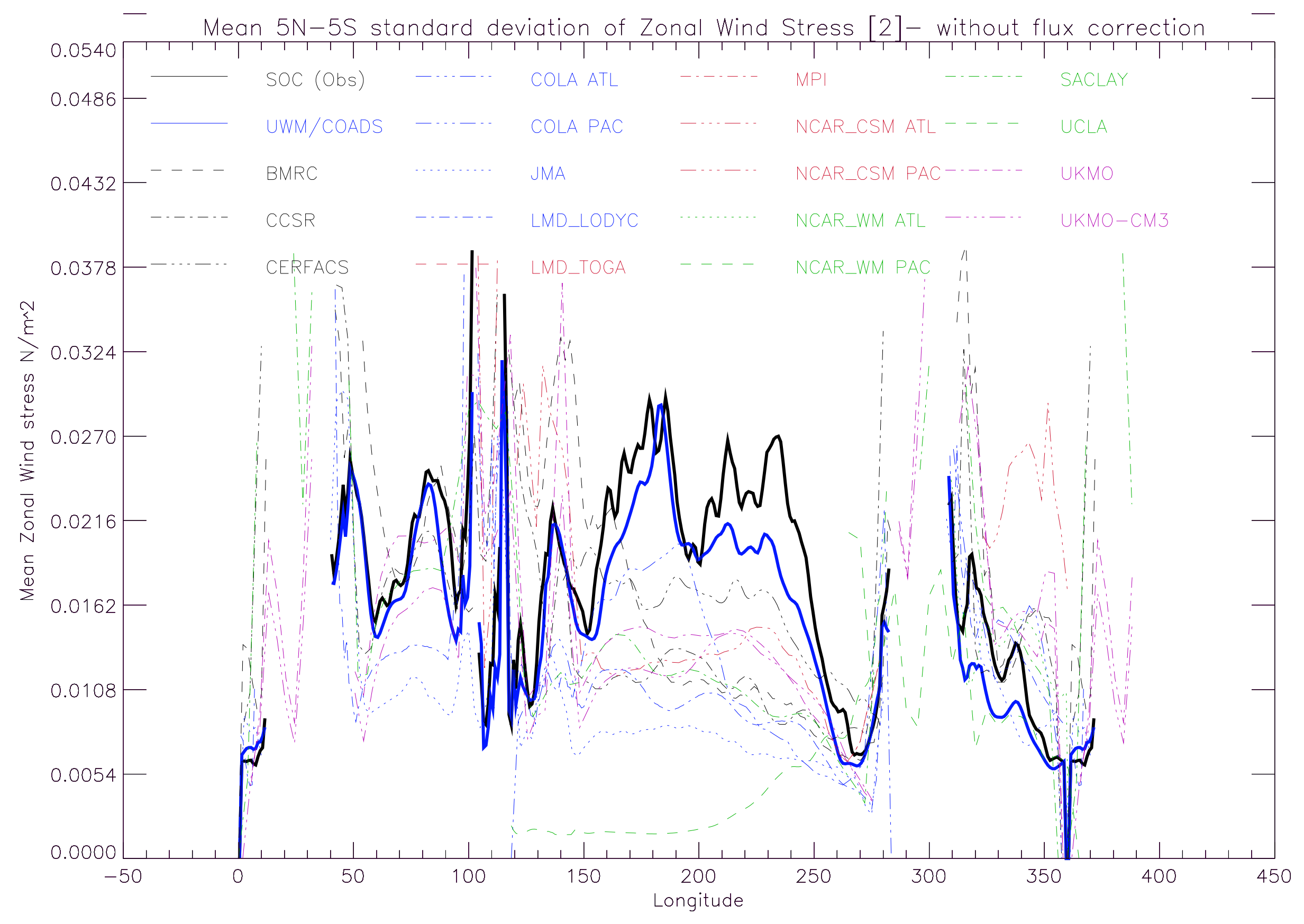

